\title{
Formación ciudadana: \\ discursos de educadores \\ y estudiantes sobre las actitudes y \\ el pensamiento crítico orientados \\ al ejercicio de la ciudadanía ${ }^{1^{*}}$
}

\author{
Pablo Alexander Muñoz García ${ }^{2}$ \\ Audin Aloiso Gamboa Suárez ${ }^{3}$ \\ Jesús Ernesto Urbína Cárdenas ${ }^{4}$
}

Fecha de recepción: 13 de agosto de 2013

Fecha de revisión: 21 de septiembre de 2013

Fecha de aprobación: 10 de octubre de 2013

\section{Resumen}

El presente artículo muestra los resultados de una investigación cualitativa-hermenéutica que pretendió interpretar los discursos de educadores y estudiantes sobre las actitudes y el pensamiento crítico orientados al ejercicio de la ciudadanía.

$1^{*}$ Artículo que presenta los resultados finales la investigación sobre Discursos y Saberes Pedagógicos, financiada por el fondo de investigación de la Universidad Francisco de Paula Santander de Cúcuta (FINU), según contrato 026 - 2011. Fecha de inicio septiembre de 2011 y finalizando en marzo de 2013.

2 Magister en Práctica Pedagogica de la Universidad Francisco de Paula Santander, hace parte del grupo de investigación en estudios sociales y pedagogía para la paz (Giesppaz), actualmente es docente y tutor de la Maestría en Práctica Pedagógica de la Universidad Francisco de Paula Santander. Correo: palmugar@gmail.com

3 Docente Investigador de la Unviersidad Francisco de Paula Santander (Cúcuta - Colombia), Magister en Pedagogía de la Universidad Industrial de Santander, doctorando en Ciencias de la Educación (Rudecolombia). Se desempeña como director y docente del programa de Maestría en Práctica Pedagógica de la UFPS. Hace parte del grupo de investigación en estudios sociales y pedagogía para la paz (Giesppaz). Correo electrónico: docaudin@gmail.com

4 Doctor en Ciencias Sociales, Niñez y Juventud del Centro de Estudios Avanzados en Niñez y Juventud del Cinde y la Universidad de Manizales. Docente y Vicerrector Académico de la Universidad Francisco de Paula Santander y Director del Grupo de Investigación en Estudios Sociales y Pedagogía para la Paz (Giesppaz) de la misma institución. Correo electrónico: jeruc24@hotmail.com 
Los resultados de esta investigación describen iniciativas caracterizadas por el verbalismo y el afán transmisionista de comunicados moralizantes. De igual modo, se destacan tendencias a hacer Educación Política como práctica verbosa (como asunto de contenidos o abordajes temáticos), al acatamiento de normas con talante heterónomo y a la escasez de la educación para el respeto, la gestión del conflicto, el compromiso social solidario y el juicio crítico.

\title{
Palabras clave
}

Formación ciudadana, pensamiento crítico, juicio crítico, gestión del conflicto.

\section{Citizenship education: statements of educators and students on attitudes and critical thinking exercise oriented citizens}

\begin{abstract}
This paper presents the results of a qualitative-hermeneutic inquiry that sought to interpret the speeches of educators and students on attitudes and critical thinking oriented citizenship. The results of this research describe initiatives characterized by verbosity and eagerness transmisionista moralizing statements. Similarly, trends do stand out as verbose practice Political Education (as a matter of content or thematic approaches), in compliance with standards heteronomous mood and scarce education for respect, conflict management, social solidarity commitment and judgment.
\end{abstract}

\section{Keywords}

Citizenship Education, critical thinking, critical thinking, conflict management. 


\section{Formação cidadã: \\ discursos de educadores e estudantes sobre as atitudes e o pensamento crítico orientados para o exercício da cidadania.}

\section{reumo}

O presente artigo apresenta os resultados de uma pesquisa qualitativa - hermenêutica que buscou interpretar os discursos dos educadores e alunos sobre as atitudes e o pensamento crítico dirigido para o exercício da cidadania. Os resultados desta pesquisa descrevem iniciativas caracterizadas pela verbosidade e a ânsia transmisionista de comunicados moralizantes. Da mesma forma, destacam-se as tendências de fazer Educação Politica como prática verbosa (como uma questão de conteúdos ou abordagens temáticas), ao cumprimento das normas com temperamento heterônomo e à escassez da educação para o respeito, a gestão do conflito, o compromisso da social solidário e julgamento crítico.

\section{Palavras-chave}

Formação cidadã, pensamento crítico, julgamento crítico, gestão de conflito.

\section{Introducción}

La formación ciudadana tiene una estrecha relación con la educación política, pues lo político, y en concreto la ciudadanía, son algo que se aprende, y se puede hablar entonces de aprendizaje ciudadano y aprendizaje político. Este es descrito por Gómez (2005) como un proceso de endoculturación política, que consiste en la producción y reproducción de significados construidos a partir de las interacciones sociales que se dan en los contextos particulares, creados por prácticas interpretativas de la comunidad a la que pertenecen los actores sociales. Tal conceptualización remite a la pregunta por las formas de apropiarse de la cultura política, que el mismo autor tipifica como: por identificación con personajes o líderes políticos, por rechazo a los valores e intereses de los grupos dominantes de la sociedad, por 
compromisos de participación activa para defender sus propias prerrogativas, por oposición o apoyo a un sistema autoritario.

Es de resaltar que la endoculturación política no se da en abstracto, sino en una comunidad de práctica que la legitima y que determina el universo simbólico de la cultura política, entendida esta como "un conjunto de 'actitudes' hacia el sistema político y sus diversas partes, y actitudes hacia el papel del individuo en el sistema" (Gómez, 2005, p. 85). De ahí que tanto el proceso de aprendizaje político, como sus contenidos, al ser un aprendizaje situado se consideren, en cita del mismo autor, ligados más a las 'características idiosincráticas' de los grupos de referencia, que a un desarrollo universal y general de estructuras lógicas; por lo que no puede reducirse la subjetividad del educador ni la del estudiante a la imagen del títere social propuesta por los teóricos de la reproducción y criticada por Giroux (2004) para enfatizar en que los actores de la práctica educativa también demuestran formas de resistencia.

Cabe anotar en este punto, que se habla de Educación Política y de formación ciudadana porque se entiende la educación como una forma de intervención en el mundo (Freire, 2006) que posibilita al sujeto y a la escuela a asumir un rol histórico (Ovelar, 2005), una determinada lectura del mundo, una particular forma de vincularse con los demás y con el contexto. A la base de esta intervención está la capacidad para la toma consciente de decisiones, por lo que toda educación resulta ideológica y lejana de cualquier neutralidad, como se ha venido repitiendo.

Uno de los problemas en este ámbito de investigación reside en que por diversos motivos mientras se realiza la práctica pedagógica, usualmente no se construye discurso sobre ella y se elude la responsabilidad de hacer pedagogía (Bedoya, 2008), de buscarle sentido profundo a la práctica pedagógica, más como praxis que como simple poiesis (hacer), en tanto que aquella implica una relación no disyuntiva entre teoría y práctica (conocimiento práctico, como la phronesis aristotélica), la deliberación y la búsqueda del bien (Carr, 2000). De este modo, este estudio intenta apoyar a la tarea de producir pedagogía, preguntándose por el discurso pedagógico-político que se expresa, según Tezanos en Bedoya (2008), en la relación pedagógica que se establece institucionalmente, la cual debe tender a romper las relaciones de poder mediante el aprendizaje y el descubrimiento.

Por su parte, con bastante claridad sobre la innegable politicidad de la educación, Freire (2006) señala algunos saberes indispensables para la práctica pedagógica-política progresista, proponiéndole al docente tener en cuenta que enseñar exige reflexión crítica sobre la práctica, reconocimiento y asunción de la identidad cultural. Insiste en que enseñar no es transferir conocimiento al estilo bancario, dado que 
enseñar exige conciencia del inacabamiento, exige el reconocimiento de ser condicionado, respeto a la autonomía del ser del educando, tolerancia y lucha en defensa de los derechos de los educadores y las educadoras, así como la convicción de que el cambio es posible. Al comprender que enseñar es una especificidad humana, plantea la necesidad de comprender que la educación es una forma de intervención en el mundo, que implica libertad y autoridad para una toma consciente de decisiones, mediada por el saber escuchar y por el reconocimiento de que la educación es ideológica.

\section{Metodología}

Los resultados que aquí se exponen hacen parte de un estudio cualitativo - hermenéutico que se realizó en la Institución Educativa de Básica y Media San Juan Bosco de la Ciudad de Cúcuta - Norte de Santander. Se utilizaron como técnicas de recolección de la información las entrevistas semiestructuradas y los grupos focales, lo cual permitió acceder a la conciencia discursiva de los participantes (Muñoz y Gamboa, 2012).

La población objeto de estudio la conformaron 18 estudiantes entre 15 y 17 años de edad teniendo como criterio de selección aquellos con permanencia de dos o más años lectivos cumplidos de género masculino y femenino y 11 docentes con el mismo criterio.

La investigación se realizó en tres fases: la preconfiguración, la configuración y la contrastación. La preconfiguración consistió en lo que Muñoz y Gamboa (2012) citando a Murcia y Jaramillo (2008) denominan delimitación del área, antecedentes y construcción de una preestructura sociocultural. En la segunda fase (configuración) se realizó el trabajo de campo consistente en entrevistas semiestructuradas y grupos focales. Por último, se desarrolló la re-configuración o también llamada contrastación en donde se evidenció la comprensión de los datos construidos con el trabajo de campo, como "redes de sentido" (Murcia y Jaramillo, 2008, p. 157).

\section{Resultados}

Dentro de los resultados de la investigación se pueden resaltar cuatro categorías de análisis importantes que se interpretarán en este aparte del artículo: el respeto por sí mismo y por los demás, la gestión del conflicto, el compromiso social, y el juicio crítico. 


\section{Respeto por sí mismo y por los demás}

Son sumamente recurrentes los discursos en los cuales los estudiantes, al diagnosticar la crisis del respeto que se da en las prácticas pedagógicas, reconocen considerar la violencia como un mecanismo eficiente para posibilitar el respeto en su cotidianidad y particularmente, cuando hay carencias de la figura de autoridad: "yo creo que por más que uno sea una persona que no molesta y siempre lo están molestando a uno, creo que uno tiene que hacerse respetar, uno tiene que aprender a pelear y no mendigar respeto".

La violencia, naturalmente, engendra temor: “( ...) si fuera un compañero grande, o alguien que apenas lo molesten, él se defiende o de pronto actúa con violencia, entonces lo respetan porque saben que si se meten con él, él va de pronto a responder con violencia". De ahí que tal vez, lo que se genere cuando esta se anuncia o se ejerce sobre el otro, no es una educación en y para el respeto sino en el miedo ante la posibilidad de ser agredido: "La verdad, para mí no se cumple; en un salón de clase es más que todo para mí como el miedo que le tengan a otra persona".

En algunos relatos, los estudiantes manifiestan que conocen otros mecanismos para ganar respeto. No obstante, al primer aviso de fracaso de esos mecanismos, se recurrirá al uso de la fuerza violenta para presuntamente ejercer así el derecho a ser respetados: “(...) primero debería ser una violencia verbal... «mire, hermano, si yo estoy quieto, yo a usted le voy a pegar, porque yo no quiero que me moleste más» y si sigue molestando, ahí sí, violencia física". Hay aquí una firme evidencia discursiva de las raíces que el terrorismo ha logrado perpetrar incluso en la escuela.

Ciertamente que ante representaciones de validez de la violencia como posibilitadora del respeto, queda en cuestión cualquier alternativa no violenta que desde las prácticas pedagógicas se haya ofrecido para vivir la experiencia de respetar y ser respetados: "siempre va a ser el hablado la mejor forma de resolver los problemas, pero si así no se puede iqué le vamos a hacer!". Y aún sostienen con mayor vehemencia y convencimiento: "(...) alguien debería de corregirlos y enseñarles cómo es que son las cosas y enseñarles a respetar. ¿Cómo?... peleando... peleando y no mendigar respeto". Al parecer, se revelan convicciones dogmáticas que desafían más aún la labor educativa en las prácticas pedagógicas, lo que suscita el interrogante de icómo educar-se en el respeto y para superar la cultura terrorista, con quien al parecer ya sabe "cómo es que son las cosas" y asume como potente imaginario que la carta bajo la manga es la violencia?

Aquí no se puede pretender juzgar las representaciones de los estudiantes como hechos aislados, perversión de las opciones personales, desviaciones 
psicológicas o imitación de estrategias terroristas por la influencia mediática. Aquí cabría hablar de un ambiente, un estilo de vida y una herencia cultural en una patria acostumbrada a que se cuente sólo la historia de los vencedores, quienes conquistaron estas tierras por la fuerza de la violencia y la opresión, y se reivindicaron cuando volvieron a empuñar la espada y a derramar la sangre del prójimo en aras de conquistar unas independencias. Estas perogrulladas que fueron inoculando al opresor dentro de los oprimidos (Freire, 2005), quienes tendrían por misión aprovechar cualquier coyuntura para invertir los roles y desquitarse de sus enemigos, los cuales no dejarían otra opción que la violencia, generaron un ecosistema sociopolítico en el que "la vulnerabilidad material y social se ha naturalizado y normalizado al punto de asumirnos como eternos y consuetudinarios sobrevivientes de la violencia" (Gómez-Esteban, 2009, p. 227), lo que podría ayudarnos a entender mejor las posiciones de los estudiantes y su deforme apreciación sobre el respeto.

Sin embargo, se hallaron discursos de resistencia que desde lo empírico rechazan la violencia y la deslegitiman como mecanismo válido para alcanzar el respeto, dada su inutilidad final:

"Pues yo opino que la violencia no es un buen medio porque si a mí alguien viene y me molesta y yo le pego... pues, después entonces esa persona va a querer tomar venganza tal vez ... motivada por la rabia que le causó que yo lo agrediera y después puede venir él a hacer lo mismo o con otra persona".

Esos enunciados afortunados parecen haber develado la lógica infame de la violencia, que no puede producir otra cosa que a ella misma. Se comprende que en aras del respeto, cuando el uso de la fuerza que vulnera se implementa, se logra sólo una interminable cadena de irrespeto; se entiende que cuando se vulnera a quienes agreden, lo único que se logra es convertirse en lo que más indigna: en el otro que lastima, en otro irrespetuoso igual.

En correspondencia, se apela a la normativa y a su seguimiento en el conducto regular para garantizar o para reivindicar el derecho al respeto como estrategia que puede funcionar dentro y fuera de las prácticas pedagógicas: "Y así, lo mismo afuera de una institución, cuando alguien tenga algún problema yo puedo hablar con esa persona y si no mirar qué procedimiento legal se puede hacer o algo, pero la violencia no es el medio correcto". Otros ven en las autoridades una mediación para reivindicar el derecho a ser respetados y el deber de respetar: 
"Yo digo que siempre en cualquier lugar va a haber como autoridad; digamos, en una institución hay un conducto regular; si pasa algo, si alguien me está molestando, yo puedo ir y hablar con el profesor; si él no hace nada, después con el coordinador y si no, con el rector".

\section{Respeto como práctica asumida con heteronomía}

Es esperable que sean los mismos estudiantes quienes logren arbitrar con autonomía las interacciones consigo mismos, con los demás y con el contexto en que se desarrollan, no por determinación de una autoridad foránea, sino porque se tiene la capacidad de reconocer legítimamente al otro, como lo estipula un proyecto denominado Jóvenes Constructores de Paz, referenciado por Alvarado y Vommaro (2010).

Con la investigación se halló justamente lo contrario. Al parecer, la promoción de actitudes como el respeto, tan básicas para el ejercicio de la ciudadanía, está en manos de los educadores y las educadoras durante las prácticas pedagógicas:

\footnotetext{
"Más que todo, los que más promueven el respeto son los profesores, que nos llaman la atención cuando hacemos cosas indebidas o hablamos en clase o cuando incluso, nos metemos con otro compañero, molestamos o pegamos, o algo así... ellos son los que nos Ilaman la atención y los que nos piden que respetemos".
}

Este tipo de intervenciones, que igual deben hacerse para garantizar la convivencia escolar, de no trascender al cuestionamiento por la autonomía de los educandos y a la correspondiente implementación de acciones correctivas autogestionadas, generan actitudes heterónomas que se derrumban ante la menor ausencia de la autoridad, y además, no garantizan un respeto legítimo, sino concepciones egoístas, propias de la minoría de edad moral que sólo pretenden lograr la evasión de la sanción (Kant, 2007). Así se relativiza el principio kantiano que aboga por una humanidad que considere al hombre como fin y nunca como medio, dejando de considerar que el respeto a la dignidad humana es "el criterio más importante en todo discernimiento moral" (Riveros et al. , 2010, p. 84).

Aun así, se descubre que en medio de esa heteronomía se intenta persuadir por el reconocimiento intencional del otro, en tanto, los informantes reconocen que las actitudes de respeto "se promueven cuando los profesores nos exigen 
hacer silencio, respetar la palabra del compañero; sí, estar... estar atento a las clases prestándoles atención a ellos y respetarnos mutuamente, que sea un respeto mutuo".

\section{La crisis del respeto en las prácticas pedagógicas}

Durante una entrevista con una educadora, ella sostenía haber observado que cuando acompañaba a los estudiantes fuera de la institución para participar en actividades interinstitucionales, estos se expresaban de manera más respetuosa que en las prácticas pedagógicas y trataba de explicar que eso ocurría en virtud de que en el colegio "como están abiertamente, como se pueden expresar en su forma, ahí es donde se infringe lo del respeto". Cabe entonces el cuestionamiento acerca de si dicho comportamiento esquizoide se origina por la falta de generación de competencias y hábitos de respeto o constituye, en el caso del comportamiento menos respetuoso en el colegio, una reacción a la violencia simbólica que ejercen las prácticas pedagógicas "en tanto que imposición, por una relación de poder, y de una arbitrariedad cultural" (Bourdieu y Passeron, 1996, p. 45).

Por otra parte, desde la perspectiva de Castillo (2003) se estima que,

"Es labor de las instituciones educativas fomentar el reconocimiento, la vivencia y la aceptación de las diferencias entre los actores sociales, por las condiciones socioeconómicas en las cuales viven, conocer y ejercer los derechos y las responsabilidades, fomentar el diálogo y el debate, en un marco de libertad de pensamiento y de acción que posibilite la confrontación, en donde se construyan consensos y disensos, teniendo como base el respeto de la persona humana" (p. 12).

Así, puede decirse que los hallazgos revelan una crisis del respeto que se atribuye, entre otras causas, a las carencias de los ambientes hogareños donde según los participantes "se pierde el respeto hacia la otra persona, y esa parte es la que le ha tocado a los colegios".

En lo concerniente a las vivencias durante las prácticas pedagógicas, la observación permitió documentar cómo "algunos estudiantes hablan mientras el educador o sus compañeros toman la palabra; ante eso, algunos estudiantes piden silencio con gestos o con ruidos, mientras que el educador algunas veces 
reconviene y otras deja que siga sucediendo". Igualmente y en este sentido, se observó que ante la denuncia de un estudiante sobre la supuesta pérdida de uno de sus libros de texto, se interrumpe la clase para buscarlo; entre tanto, se aprovecha para hacer un recuento de todo lo que presuntamente se han robado del salón y que no ha sido recuperado. El profesor advierte que si no aparece el libro, todos deberán pagarlo.

Este tipo de actitudes vacilantes o muy formales frente a la promoción del respeto, da lugar a prácticas pedagógicas en las que según otra observación "se profieren insultos con groserías entre estudiantes (mientras) la docente continúa su clase ignorando a propósito la situación", lo cual afecta directamente el alcance de un modelo de comunicación favorable para la paz (Martínez, Comins y París, 2009).

Incluso desde la misma observación puede llamarse al engaño cuando intencionalmente tomando nota de las vivencias del respeto en una práctica pedagógica, se apunta: "Se observa que cuando algunos estudiantes intervienen en clase para hacer aportes argumentados y propios, los demás atienden en actitud de silencio". Esto no resulta más que una forma de sumisión o una carencia de herramientas para asumir una actitud alternativa y divergente, en tanto que según el estudio de Monroy (2006) el respeto se puede confundir con el silencio, dado que en algunas respuestas se intuyeron falencias en la capacidad argumentativa de los interlocutores mientras se desarrollaba un taller sobre el respeto.

Otras referencias de la crisis, que parece agudizarse progresivamente según los informantes, cuenta que las prácticas pedagógicas “(...) Ilegan a un punto, que ya ni los estudiantes respetan a los profesores", por lo que desde lo empírico pronostican que si "no son capaces de respetar a los compañeros, menos van a ser capaces de respetar a un profesor". Eco y explicación de lo anterior, trata de hacer una educadora que critica la vivencia del respeto en las prácticas pedagógicas afirmando que: “(...) también de parte de los profesores, se utilizan muchos apodos que no deben estar ahí, o sea también si nosotros empezamos con esos apodos, pues lógicamente los muchachos también".

Esto resulta aún más caótico para el éxito de una Educación Política si se lee desde el Informe de McKinsey y Company, quienes estudiaron recientemente las características de los mejores sistemas educativos del mundo: "En particular, los observadores externos atribuyen a menudo el éxito de los sistemas educativos asiáticos que estudiamos a dos factores: una fuerte ventaja cultural en educación y el tradicional respeto por el docente" (Barber y Mourshed, 2007, p. 20). 


\section{Posibilidades para nuevos textos sobre el respeto}

Distinta de los anteriores hallazgos es la concepción de una educadora, que se documentó durante una de las prácticas de observación en la que al inicio de la clase, la profesora revisa uniformes y les recuerda a los estudiantes la importancia de estar bien presentados, "como muestra de amor propio" y como gesto de respeto a sí mismos, a los compañeros y al colegio.

Se aprecia pues, que aquí el acento está puesto en la subjetividad política de los estudiantes, más que en la norma, lo que permite colegir también que se comprende, en coincidencia con Riveros et al. (2010) que “(...) a través de la reciprocidad se pasa del interés privado al respeto de la humanidad" (p. 81).

En esa línea de la reciprocidad como experiencia práctica para la promoción del respeto desde las prácticas pedagógicas, al cual sin embargo en los discursos de los informantes se le sigue reconociendo su importancia, se invita a ver el respeto a modo de proceso, el cual va apareciendo como fruto del testimonio de los educadores y las educadoras en tanto que, como ellos afirman, "el respeto propio es algo que se tiene que ir construyendo poco a poco con los estudiantes".

Decididamente desde las prácticas pedagógicas se ve la necesidad de incidir a mayor profundidad en el acompañamiento que persuade a los jóvenes acerca de aquellos “(...) principios de humanidad que justifican los deberes morales y las acciones ciudadanas de mantenimiento de la democracia sobre la base de la igualdad, el reconocimiento, la equidad y el respeto" que se han encontrado en estudios sobre responsabilidad moral y política en los jóvenes (Echavarría et al., 2009 p. 1455 y Henao y Pinilla, 2009) y que escasean en la institución.

\section{Gestión del conflicto}

Es necesario partir de la referencia sociopolítica nacional para comprender el sistema de ideas y poderes que posibilitan las representaciones sobre la microsociedad abordada en esta investigación, sobre el conflicto. Baste para ello hacer referencia a dos elementos: el primero de ellos es la constatación de vivir en una sociedad donde el conflicto armado celebra ya más de seis décadas y aún se sigue considerando que es la vía armada el modo de resolverlo (Henao y Pinilla, 2009), incluso 
resucitando la vieja doctrina de seguridad nacional que justifica atrocidades hijas de la violencia como el terrorismo, el secuestro, la extorsión, los falsos positivos o la toma de la justicia por mano propia a través de grupos criminales emergentes, muchas veces con la complicidad de los gobiernos y los parlamentarios (León, Reyes y Baquero, 2008). El segundo es el señalado en el más reciente informe nacional de competitividad (Compite, 2010), desde el que se enuncian las serias deficiencias que tiene el Estado colombiano para resolver los conflictos de sus ciudadanos que son llevados a instancias del ministerio público, lo que nos permite colegir que nos movemos en comunidades de práctica con visiones negativas del conflicto y con notables incapacidades para gestionarlo.

En el plano específicamente juvenil, estudios como el de Monroy (2006) haIlan justamente que en ese sector poblacional vinculado a las realidades escolares es frecuente encontrar que, "(...) o bien optan por el diálogo o por ignorar el problema, o, con la honestidad propia de su edad, asumen que la agresividad también es una forma de afrontar el conflicto" (p. 48), como también halló esta investigación en el dominito anteriormente tratado.

\section{Visión «naturalista» sobre el conflicto}

Se hallaron perspectivas desde las que se concibe el conflicto como algo producido con base en las intrínsecas diferencias de pensamientos y de actitudes, que se provoca a veces incluso a partir de lo que habitualmente pudiera considerarse poco significativo desde el punto de vista de los participantes

"Pues... una parte puede ser normal porque cada uno... o sea, piensa diferente; el conflicto a veces se produce por diferentes temas, porque es la verdad; un conflicto (se da) porque esa persona piensa diferente o porque esta me quitó a esta persona o porque esta no me respetó... así se va produciendo el conflicto. Un conflicto es cuando dos personas tienen diferente punto de vista hacia una cosa, o sea, un problema se desemboca cuando dos personas no están de acuerdo. Pues, es normal que se vea a diario, porque todas las personas no piensan de la misma forma".

Incluso, esa "conflictividad normalizada", puede abrir espacio a manifestaciones violentas, como sostienen los informantes en el siguiente enunciado: “(...) y 
se produce un problema y ese problema no se resuelve dialogando, entonces se produce violencia".

Esa narrativa que habla del conflicto como algo natural en la experiencia humana en general y en la vivencia de las prácticas pedagógicas en particular, se constituye en el "(...) punto de partida de cualquier análisis y propuesta educativa científica y ético-política" (Gómez, 2005, p. 168). Además, parece coincidir con el análisis social, político y pedagógico que hiciera Marco Raúl Mejía (2001, p. 33) sobre el mismo dominio en el contexto escolar:

"Una vez que conocemos la experiencia del conflicto nos queda la certeza de que siempre está ahí, agazapado para presentarse a la menor oportunidad. Parece que hubiéramos nacido para él y es allí donde reconocemos la raíz del conflicto: en los más variados escenarios de mi ser en el mundo y que reconozco también como los niveles en donde es construida y manifiesta mi individuación- socialización" (Mejía, 2001, p. 33).

\section{Conflicto y violencia}

En los discursos hallados pudo encontrarse que se trascienden visiones miopes acerca del conflicto, en tanto que los informantes tienen claro que "una cosa es conflicto y otra cosa es llegar a la violencia". Alcanzan incluso a tener una visión menos esencialista del conflicto: “(...) es cuando dos personas poseen un problema, pero el problema no es el que ellos tienen, el problema es cómo solucionarlo", por lo que se asume que los informantes comprenden que "el conflicto no es bueno o malo, es moralmente neutro. La manera como lo asumimos hace que sea bueno o malo y la manera como lo colocamos en el entramado social" (Mejía, 2001, p. 34).

Refieren además, que en las prácticas pedagógicas se inculca con ahínco "tener un diálogo con la otra persona antes de recurrir a cualquier otro método, porque nos dicen siempre, que la violencia genera más violencia y que nosotros somos unos seres que pensamos, que razonamos". Al parecer, en este sentido las prácticas pedagógicas han sido bastante explícitas e incisivas pues además de la distinción conceptual y argumentada que manifestaron los informantes entre conflicto y violencia, los ademanes que acompañaban las expresiones sobre lo aprendido al respecto, denotaban convicciones y seguridad como base del discurso. 


\section{Diálogo y mediación para gestionar conflictos}

García, Betancur y Arango (2011) en su investigación, encontraron que recurrentemente en la escuela se buscan alternativas de solución no violentas y distintas a las basadas en la aplicación de sanciones y castigos, que es lo que pretende el discurso de las competencias ciudadanas al buscar que se enfrenten los conflictos de modo pacífico y constructivo (Mejía y Perafán, 2006).

En coincidencia, eso fue lo que halló la presente investigación, al encontrar que en las prácticas pedagógicas es habitual recurrir al diálogo y a la mediación para gestionar el conflicto, como describe una educadora a continuación:

“¿Cómo se resuelve un conflicto en una clase? Dialogando con el muchacho, apartándolo, en esos momentos está la temperatura caliente, están los ánimos alterados, hay que esperar que se calme un poquito, sacarlo del salón, o del aula, del espacio donde esté y hablar nuevamente con el muchacho, y hacerle caer en cuenta de los errores que ellos tienen, a mí siempre me ha funcionado y me parece que ellos lo acatan con mucha humildad, y se solucionan los conflictos".

De no hallar solución en primera instancia, como es lo ideal, se suele recurrir a otros mediadores con función directiva en el colegio. Sin embargo, los mismos educadores reconocen la importancia del papel de los pares en la mediación de los conflictos habituales al señalar que:

"En la mayoría de las ocasiones he notado cómo los muchachos hoy en día, inclusive los que están alrededor del conflicto quieren ayudar, actúan para que el conflicto no sea más grande, cuando hay una agresión física entre alguno de los compañeros siempre en todos los casos los demás actúan, interviene para que ese conflicto no sea mayor, y ellos en ese momento se calman y los compañeros siempre colaboran: «mire, no pelee, no haga esto, no conteste, espérese, espérese» y ellos esperan a calmar los ánimos, pero lo que más me gusta es que los demás ayudan para resolver esos problemas, ya que tienen esa capacidad como de entender que generando o ayudando a encender ese fuego no lo van a solucionar, lo que hacen es apaciguar los ánimos de los demás".

Cabe citar aquí una situación captada a través de las observaciones, acerca de un conflicto entre unas estudiantes (en el cual al parecer el educador ya había mediado anteriormente), que se atiende recordando los antecedentes del mismo, 
y se afirma por parte del educador que el origen está en el chisme. Desde la observación se percibe inconformidad persistente entre las implicadas y que la carencia del diálogo podría invitar a pensar que dicho conflicto puede continuar. Este tipo de circunstancias propias de la realidad empírica de la escuela, son aprovechadas por Mejía y Perafán (2006) para criticar que el discurso de las competencias ciudadanas presume sin reparos que los actores del conflicto han desarrollado suficientemente competencias comunicativas para superar mediante el diálogo las asimetrías de poder, lo cual resulta ingenuo en la medida que mientras tanto el desarrollo sensato de esas competencias dialógicas no se produzca, el perjuicio de un conflicto no bien gestionado seguirá vulnerando a las partes.

\section{Posibilidades para nuevos textos sobre gestión del conflicto}

Al respecto de la gestión del conflicto en las prácticas pedagógicas, Giroux asume que

“(...) los conflictos y las contradicciones deben ser estudiadas y analizadas por los maestros como cuestiones a ser problematizadas y usadas como puntos de discusión y como vehículos para conectar las prácticas del salón de clases con las cuestiones políticas más amplias" (2004, p. 254).

En relativa coincidencia, desde los discursos de los informantes se propone para las prácticas pedagógicas asumir la educación para la gestión del conflicto y tomar como referente experiencias exitosas al respecto, promoviendo una perspectiva que describen como más madura, para "entender que a veces nosotros vemos un conflicto donde no lo hay" (afirma un estudiante en un grupo focal) y fortaleciendo la formación axiológica para lograr precisar lo esencial en los conflictos.

Sí, las apuestas se orientan a convertir el conflicto en dispositivos educativos y pedagógicos que visibilicen intereses de poder e ideologías que entran en juego cuando este se produce (Mejía, 2001). 


\section{Compromiso social y espíritu solidario}

\section{Solidaridad: ¿transacción académica o soborno?}

Echavarría et al. (2009) encontraron que en el mundo juvenil, la responsabilidad ciudadana es asociada y vivida con un sentido moral y político de solidaridad y consideración de la alteridad. En contraste con dicho hallazgo, este trabajo encontró que la promoción del compromiso social y la solidaridad están mediados por el otorgamiento de prebendas como calificaciones beneficiosas y adicionales para quienes participen, dejando claro que de lo contrario no habrá participación: "Eh... pues, en las clases sí se promueve, pero se promueve es por el sentido de una nota (...) de igual forma los profesores también saben".

Otra manera de hacer transacción académica que se suele considerar estímulo, es la prestación del servicio social obligatorio, como sostienen los informante: "En el salón, no hay mucho incentivo en este tipo de ayudar a los pobres, pues... aparte del salón, el Colegio ya por lo menos, (si acaso) para los muchachos de diez y de once, que tenemos que cumplir con unas horas de servicio social".

Ese tipo de soborno goza de justificación en algunos discursos de los informantes, quienes justifican los medios en aras del fin, en tanto refieren que: "Pues... en cierta manera, sí nos incitan a esto, porque así dándonos algo a cambio, así sea una nota, nos están diciendo que colaboremos, que ayudemos".

Otras posturas más radicales apenas logran distinguir un grupo de prácticas pedagógicas que alientan la formación en pastoral y desarrollo humano, como promotoras del compromiso social y la solidaridad:

"Pues, en realidad la única que medio, medio cultiva es la clase de ética y religión, de resto ninguna otra clase nos ha hecho; ni ofreciéndonos incentivos, nos ha propuesto la idea. Las únicas que medio nos han propuesto la idea son las profesoras de Pastoral, que nos han dicho que vayamos, que colaboremos en esto o aquello; pero, de resto, ver a otras personas en esta labor, no".

Al respecto es necesario expresar que la asunción de compromisos sociales y la promoción del espíritu solidario son tópicos escasamente abordados en los estudios sobre Escuela y política en educación media a los que se tuvo acceso para este trabajo investigativo. Más ausente aún resulta el problema de las transacciones académicas y del soborno, que aquí se ha asumido como el hecho de persuadir a alguien para obtener alguna actitud, mediante el otorgamiento de dádivas, lo cual bien podría 
confundirse con el estímulo o la motivación, pero que en el campo académico le da un carácter mercantilista a las calificaciones, pervierte el objetivo evaluativo de las notas y en el campo político bien puede identificarse como una acción de corrupción en tanto se da el otorgamiento de beneficios privados no estipulados con legitimidad ni con legislación, por una intervención de carácter público.

\section{Sensibilización y educación verbosa}

En el estudio se encontraron alusiones a prácticas pedagógicas que han propendido por la sensibilización de la Comunidad Educativa Pastoral hacia sectores socioeconómicamente vulnerables de la ciudad, las cuales han devenido experiencias eficaces en ese sentido: “(...) uno los lleva a algún lugar y de acuerdo a lo que ellos observan, ellos dicen "profe podríamos hacer esto, o podríamos hacer aquello en pro de tal cosa, o de tal persona»". Esas intervenciones se aprecian en alto grado de parte de los educadores y las educadoras, quienes manifiestan ser conscientes de que así se produce una formación que trasciende la información que se pueda lograr a través de medios como Internet. De igual manera, se enuncia que tal tipo de acciones han permeado a la totalidad del estudiantado:

\footnotetext{
"Eso en lo social los estudiantes siempre están dispuestos a colaborar, a ir a las comunidades más necesitadas, incluso acá en el colegio no hay un solo estudiante que no haya conocido parte de esa problemática, sobre todo allá en el oratorio, son muy solidarios con las demás personas, porque cada vez que se hace una campaña para recoger mercado, regalos, ellos siempre están ahí aportando su grano de arena".
}

Se le da, pues, tanta importancia a la trascendencia de este tipo de experiencias intencionadas, que se ofrecen explicaciones orientadas a afirmar que "(...) de pronto no lo hacen porque no la conocen, porque no conocen la realidad que tiene la ciudad, no es porque no quieran, sino porque no la conocen, eso no los toca a ellos". Aquí se visibilizan dos representaciones. Una que no se pueden atribuir las carencias del compromiso social de los estudiantes (reseñadas en el apartado anterior) a las ausencias afectivas de ellos hacia la solidaridad con los empobrecidos. Otra, que el desconocimiento y la falta de contacto vivencial con las realidades sociopolíticas neurálgicas explica las carencias a las que se viene haciendo alusión. 
Al respecto del mismo asunto, se hallaron discursos que hacen referencia a ciertas formas de promover el compromiso social y la solidaridad, basados en el verbalismo, dando por hecho que esas dos realidades se dan desde la práctica pedagógica, porque se habla de ello y porque es característico del discurso de una educación constitutivamente católica: “(...) este es un colegio católico y aquí se habla mucho de solidaridad, se habla mucho de tener en cuenta la necesidad del otro".

Incluso, cuando se interrogó por estrategias para optimizar ese tópico específico en la educación de los estudiantes para el ejercicio de la ciudadanía, se aludió a que "constantemente se les debe hablar a ellos en clases acerca de lo bueno que es ser un honesto ciudadano, de la recompensa que uno recibe más adelante cuando uno hace las cosas correctas".

Desde otra perspectiva se hizo alusión a las «campañas» a favor de ciertos sectores sociales vulnerables, las cuales se reducen al abordaje temático de temas relacionados con la drogadicción y con los niños que no tendrían un juguete en Navidad.

Puede colegirse entonces, que este dominio de la Educación Política en la comunidad de práctica sujeto de la investigación, está supeditado a la presencia o ausencia de tiempos para su abordaje meramente temático y adolece de lo que Paulo Freire (2002) denunciaba en uno de sus textos clásicos al señalar que "nuestra educación no es teórica, porque le falta ese apego a la comprobación, a la invención, al estudio. Es verbosa, es "palabrería", es "sonora», es "asistencialista", no comunica; hace comunicados, cosas bien diferentes" (p. 89).

\section{Posibilidades para nuevos textos sobre compromiso social y solidaridad}

Desde los relatos construidos, se propende por optimizar la educación en valores, trascender el claustro, fomentar el contacto con realidades socialmente vulneradas, realizar trabajos en sinergia con otras instituciones y desarrollar trabajos académicos de campo u orientados desde las necesidades del contexto para vehiculizar la educación para el compromiso social y la solidaridad, desde constataciones recurrentes como la que narra una educadora:

\footnotetext{
"Nosotros estamos acá encerraditos en una caja de cristal donde solamente vemos lo que está a nuestro alrededor, que es lo más normal, estudiantes con su papás y con su familia muy normal a todo lo que ellos tienen acá, pero hay que sacarlos a ver la realidad de la ciudad, no todo lo que está alrededor de la ciudad es bonito".
} 
Este planteamiento de la necesidad de proyección en la realidad social es compatible con la visión de Giroux (2004), para quien "la acción social es necesaria, pero debe ser precedida por precondiciones subjetivas que hacen inteligible la necesidad de tal acción" (p. 253), lo que llama la atención sobre el compromiso de las prácticas pedagógicas con la formación de conciencia social en tanto esta se constituye en posibilidad para la actuación como ciudadanos comprometidos, desde una actitud crítica con el orden social próximo y con el global.

En este sentido de formación de conciencia, se halló que la misma actividad investigativa del presente trabajo provoca en los educadores y las educadoras la crítica a las actuales prácticas pedagógicas en el sentido del dominio estudiado, así como la propuesta de alternativas para su radical transformación:

"Tendríamos que cambiar por completo el concepto de estar en el aula, ya no sería aula y tablero y pupitre, tendríamos que salir a hacer trabajos de campo para tener experiencias escritas en libretas, a tener un seguimiento a aquellas entidades o personas con las que estemos trabajando, los contenidos de la clase tendrían que cambiar, tendrían que girar y tendrían que enfocarse más a aquellas prácticas y tratar de irlos vinculando con cada una de esas experiencias, tendríamos que reformar esa parte de planear la clase dentro del salón, sino mirarlo ya desde una experiencia práctica".

\section{Juicio crítico}

La autenticidad manifestada en un juicio propio y fundamentado acerca de la realidad sociopolítica, define las tendencias más marcadas de las prácticas pedagógicas que promueven la configuración del juicio crítico, como refiere por ejemplo un estudiante durante un grupo focal: “(...) nos enseñan a tener nuestro propio criterio, nuestro propio pensamiento".

Otro explica cómo ocurre dicha configuración:

"Sí se nos forma para tener capacidad de crítica, pues eso lo hacen algunos docentes; a veces, se discute un tema de la realidad social y que ocurre fuera de la institución y nosotros expresamos nuestras dudas y cuestionamos lo que está ocurriendo o por medio de opiniones y se habla de temas, como qué opinan sobre... digamos, que hayan drogas o que hayan aumentando los robos en tal institución; o que... digamos, el deterioro de las vías de la ciudad y todas esas cosas; mediante opiniones nosotros expresamos y hablamos de diferentes realidades que se presentan en el país y en algunas clases". 
Desde la perspectiva de los educadores y las educadoras se alude al empleo de la pregunta como detonante de dispositivos pedagógicos en los que se pueda educar el juicio de los estudiantes para la criticidad. Esta posibilita el desarrollo de habilidades para hacer opciones y elegir candidatos, así como para proponer alternativas de solución en lo social.

Desde las prácticas de observación, por ejemplo se apreció que "durante la socialización de avances en las investigaciones, algunos de los estudiantes aportan su visión personal de las problemáticas de frontera. Otros se limitan a leer las diapositivas, que retransmiten datos sociodemográficos consultados". De igual manera se observó que "el educador interpela a los estudiantes para que tomen posición frente a lo que se está comentando", muy en la línea de lo que propone Freire (1998) al comentar que la necesaria enseñanza de los contenidos no debe descuidar el conocimiento crítico de las circunstancias históricas del conocimiento que se estudia ni de las condiciones en que se da el proceso de enseñanza-aprendizaje.

\section{Posibilidades para nuevos textos sobre el juicio crítico}

"Es preciso y hasta urgente que la Escuela se vaya transformando en un espacio acogedor y multiplicador de ciertos gustos democráticos como (...) el gusto por la pregunta, por la crítica, por el debate" (Freire, 1998, p. 98). Desde esta concepción, es viable implementar en las prácticas pedagógicas, dispositivos en los que se pueda orientar a los estudiantes en la superación de su experiencia de vida caracterizada porque "de pronto su mentalidad está encasillada solo en problemas naturales que tiene un joven", como afirma una educadora.

Otras apuestas se orientan a continuar con las actividades de discusión en las que se vinculen a expertos foráneos, así como el fomento de la participación en instancias interinstitucionales de discusión y apropiación de realidades sociales problemáticas, con base en la implementación de la pregunta como estrategia para el aprendizaje significativo en la resolución de problemas (Ortiz, 2009).

\section{Conclusiones}

Los discursos acerca del fomento de las actitudes y el pensamiento crítico orientados al ejercicio de la ciudadanía en las prácticas pedagógicas de la educación 
media del colegio, describen iniciativas caracterizadas por el verbalismo y el afán transmisionista de comunicados moralizantes. De igual modo, se destacan tendencias a hacer Educación Política como práctica verbosa (como asunto de contenidos o abordajes temáticos), al acatamiento de normas con talante heterónomo y a la escasez de la educación para el respeto, la gestión del conflicto, el compromiso social solidario y el juicio crítico. A lo largo de los discursos se puede leer una crisis en la asunción práctica de valores como el respeto, el pacifismo, la solidaridad y la criticidad. No obstante, también se revelan prácticas en las que se proponen alternativas a las tradicionales formas de educar para actuar y pensar el ejercicio de la ciudadanía, fundadas en el raciocinio, el diálogo y la autenticidad.

Con relación a la promoción que las prácticas pedagógicas de educación media hacen del respeto, se enuncia que se conocen alternativas y medios para garantizar la vivencia del respeto por sí mismo y por los demás, mas tal realidad se llega a producir, pero por el temor que existe en la comunidad de práctica a recibir agresiones de parte de las víctimas; es decir, que los discursos declaran que aunque se conocen otros mecanismos que posibilitan el respeto, como el diálogo y la mediación de terceros, al menor indicio de fracaso en ese sentido, se acudirá al ejercicio de algún tipo de violencia y se entiende que por tal motivo es que algunos se abstienen de irrespetar, para no ser violentados por quienes se sienten irrespetados.

Los discursos alusivos a la educación en y para la gestión del conflicto lo entienden como un acontecimiento recurrente en las relaciones humanas, que resulta tan natural como las diferencias interpersonales, en las prácticas pedagógicas de la educación media en el colegio. Desde esa perspectiva, se comprende que lo importante del conflicto es el problema que hay de fondo y las tareas a realizar para resolverlo como se promueve en la comunidad de práctica inmediata: mediante el diálogo y la mediación.

La educación para la producción del juicio crítico es concebida en los discursos como algo que se construye promoviendo la manifestación de juicios propios y argumentados sobre la realidad sociopolítica a partir de la interpelación heurística, así como haciendo propuestas de solución, demostrando capacidad de opción, de votación y de ponderación de argumentos. No obstante, aunque se favorece la intervención desde las opiniones personales, la promoción del juicio crítico tiene un sesgo moralizante que resulta una contradicción en tanto parece enunciar respuestas prefabricadas y recetas para toda problemática. Desde estos discursos configuradores en las prácticas pedagógicas, se aboga por acompañar a los estudiantes en 
la superación de la reducción de la realidad a problemas personales propios de su adolescencia, a partir de preguntas generadoras de discusiones, la intervención en eventos interinstitucionales a propósito, y la consulta a expertos.

\section{Referencias Bibliográficas}

Alvarado, S. y Vommaro, P. (2010). Jóvenes, cultura y política en América Latina: algunos trayectos de sus relaciones, experiencias y lecturas (1960-2000). Santa Fe: CLACSO - Homo Sapiens.

Bedoya, (2008). Epistemología y pedagogía. Bogotá: Ecoe Ediciones.

Barber, M. y Mourshed, M. (2007). Cómo hicieron los sistemas educativos con mejor desempeño del mundo para alcanzar sus objetivos. McKinsey y Company, Recuperado de http://www.eduteka.org/informeMcKinsey.php

Bourdieu, P. y Passeron, J.-C. (1996). La Reproducción. Elementos para una teoría del sistema de enseñanza. México: Distribuciones Fontamara, S.A.

Castillo, (2003). La formación de ciudadanos: La escuela, un escenario posible. Revista Latinoamericana de Ciencias sociales niñez y juventud. Vol. 1, No. 2, 1 - 16.

Compite (2010). Informe Nacional de Competitividad 2010 - 2011. Bogotá: Consejo Privado de Competitividad Colombia.

Carr, W. (2000). Una teoría para la educación. Hacia una investigación educativa crítica. Madrid: Ediciones Morata S.L.

Echavarría, C., Restrepo, P., Callejas, A., Mejía, P. y Alzate, Á. (2009). La responsabilidad moral y política: una mirada juvenil. Revista Latinoamericana de Ciencias Sociales, Niñez y Juventud. Vol. 7, №. 2, 1439-1457.

Freire, P. (1998). Cartas a quien pretende enseñar (4 ed.). México: Siglo XXI Editores.

Freire, P. (2002). La educación como práctica de la libertad (L. Ronzoni, Trans. 11a. ed.). Madrid: Siglo XXI de España Editores, S.A.

Freire, P. (2005). Pedagogía del Oprimido. México: Siglo XXI Editores, S.A. de C.V.

Freire, P. (2006). Pedagogía de la Autonomía. México: Siglo XXI Editores.

García, A., Betancur, L. y Arango, C. (2011). La escuela emergente: tejido de relaciones espaciales. Medellín: Universidad Autónoma Latinoamericana Unaula.

Giroux, H. (2004). Teoría y resistencia en educación. Una pedagogía para la oposición. México: Siglo XXI Editores.

Gómez, J. (2005). Aprendizaje ciudadano y formación ético-política. Bogotá: Fondo de Publicaciones Universidad Distrital Francisco José de Caldas. 
Gómez-Esteban, J. (2009). Humanización: hacia una educación crítica en Derechos Humanos. Universitas Psychologica. Vol. 8, №. 1, 225-236.

Henao, J. y Pinilla, V. (2009). Jóvenes y ciudadanías en Colombia: entre la politización social y la participación institucional. Revista Latinoamericana de Ciencias Sociales, Niñez y Juventud. Vol. 7, №. 2, 1405-1437.

Kant, (2007). Fundamentación de la metafísica de las costumbres. México: Editorial Porrúa.

León, I., Reyes, P. y Baquero, S. (2008). Una mirada hermenéutica a la cultura política en Latinoamérica y en Colombia. Bogotá, D.C.: Facultad de Derecho, Ciencias Políticas y Sociales, Universidad Nacional de Colombia.

Martínez, V., Comins, I. y París, S. (2009). La nueva agenda de la filosofía para el siglo XXI. Estudios para la paz. Convergencia. №. 19, 91-114.

Mejía, M. (2001). Construir educativamente el conflicto. Hacia una pedagogía de la negociación cultural. Nómadas. №. 15, 24-39.

Mejía, A. y Perafán, B. (2006). Para acercarse al dragón, para amansarlo, es necesario haberlo amansado primero: una mirada crítica a las competencias ciudadanas. Estudios Sociales, No. 23, 23-35.

Monroy, B. (2006). La escuela en la formación de la esfera pública. Una estrategia pedagógica para la formación de cultura política en los espacios escolares. Bogotá: Universidad Externado de Colombia - Instituto para la investigación educativa y el desarrollo pedagógico, IDEP.

Muñoz, P. y Gamboa, A. (2012) Escuela y Educación Política: Una mirada a los imaginarios de actores educativos. Pedagogía y Saberes. Vol. 36, 135 - 143.

Murcia, N. y Jaramillo, L. (2008). Investigación cualitativa: La Complementariedad. Armenia: Kinesis.

Ovelar, N. (2005). Educación, política y ciudadanía democrática. A través de la especial mirada de Paulo Freire. Revista de Pedagogía. Vol. 26, № 76, 187-206.

Ortiz, A. (2009). Pedagogía Problémica: modelo metodológico para el aprendizaje significativo por problemas. Bogotá: Editorial Magisterio.

Riveros, C., López, E., Quintero, M. y Salazar, W. (2010). Orientaciones Pedagógicas para la Filosofía en la Educación Media. Bogotá, D.C.: Ministerio de Educación Nacional. 
